\title{
PHYSICAL TRAINING METHODS FOR MINE RESCUERS IN 2015
}

\author{
COSTA Cristian, \\ Faculty of Science, Department of Social Science, University of Petrosani, Petrosani, \\ Romania, cristyc73@yahoo.com
}

\author{
LUPU Lucian, \\ Faculty of Mining, Department of Mining, Surveying and Construction, University of Petrosani, Petrosani, \\ Romania, lupu_lucian@yahoo.com
}

EDELHAUSER Eduard,

Faculty of Mining, Department of Management, University of Petrosani, Petrosani, Romania,edi1ro2001@yahoo.com

\begin{abstract}
We have studied physical mine rescue training programs and health-related and rescue-related fitness tasks during a mine rescue competition, made in China and Australia and on these basis we have design our own pre physical training method. We have stored the heart rate measured in bites per minute (bpm) during the 2012 year periodical training for 21 mine rescuers. We have designed a physical training procedure based on six training models: Body Building, Method of isometric efforts, Method of Interval Training, Volume variation method, Structured method for basic grip and release and Specific work method. Then we measured again during the 2014 year periodical training, the heart rate for the same mine rescuer having the physical training procedure performed before. We have notice that the trained person have now lower bpm, during the tests that could represent better performances during the rescue actions. Our research were made in the Laboratory for Risk-Rescue Operations of the INCD INSEMEX Petroșani, Romania.
\end{abstract}

Key words: mine rescuer, training programs, physical training procedure, heart rate monitors, increase efficiency

\section{Introduction}

Mining laws in developed countries require trained, equipped mine rescue personnel to be available at all mining operations at surface and underground mining operations. Mine rescue teams must know the procedures used to rescue miners trapped by various hazards, including fire, explosions, caveins, toxic gas, smoke inhalation, and water entering the mine. Most mine rescue teams are composed of miners who know the mine and are familiar with the mine machinery they may encounter during the rescue, the layout of workings and geological conditions and working practices [8]. Local and state governments may have teams on call ready to respond to mine accidents. In our paper we have presented some of the newest training methods in countries where mine rescue has more than 100 years history. We have presented a few researches made by our collective in 2012 - 2014 year with heart rate monitors and GPS sport watches over 21 mine rescuers trained in the Laboratory for Risk-Rescue Operations of the INCD INSEMEX.

\section{Literature review}

In a study made in 2008 year by Ian B Stewart, Michael D McDonald, Andrew P Hunt and Tony W Parker, and published in the Journal of Occupational Medicine and Toxicology under the name "Physical capacity of rescue personnel in the mining industry", they studied 91 rescue personnel (34 \pm 8.6 yrs, $1.79 \pm 0.07 \mathrm{~m}, 90 \pm 15.0 \mathrm{~kg}$ ) participating in the Queensland Mines Rescue Challenge, Australia, they completed a series of health-related and rescue-related fitness tasks [10]. Health-related tasks comprised measurements of aerobic capacity $\left(\mathrm{VO}_{2} \mathrm{max}\right)$, abdominal endurance, abdominal strength, flexibility, lower back strength, leg strength, elbow flexion strength, shoulder strength, lower back endurance, and leg endurance. Rescue-related tasks comprised an incremental carry (IC), coal shovel (CS), and a hose drag (HD), completed in this order. As a result they concluded that Cardiovascular $\left(\mathrm{VO}_{2} \max \right)$ and muscular endurance was average or below average compared with the general population. 
Isometric strength did not decline with age. The rescue-related tasks were all extremely demanding with heart rate responses averaging greater than $88 \%$ of age predicted maximal heart rates. Health-related fitness was measured by assessing the following attributes: aerobic capacity $\left(\mathrm{VO}_{2} \mathrm{max}\right)$, abdominal endurance, abdominal strength, flexibility, lower back strength, leg strength, elbow flexion strength, shoulder strength, lower back endurance, and leg endurance. Abdominal endurance was measured as the number of completed sit ups in 60 seconds [9]. Lower back endurance was assessed by the BieringSorensen test [10]. Maximal isometric strength was assessed with a customised strain gauge system linked to a computer program (LabVIEW, National Instruments, Austin, TX). The subjects performed a seated row, dead lift, standing shoulder press and bicep curl exercises. Force generated (kg) was obtained from a three second maximal effort. Abdominal strength was assessed as the number of different variations of sit up successfully completed. Seven different variations of sit up were used, each of an increasing difficulty. The subject attempted each one in order, until they could not complete a particular variation. The last successfully completed stage was recorded as their abdominal strength score [9]. Flexibility was assessed via the sit-and-reach test [1]. Based on their conclusions that: Mines rescue requires strenuous effort at sporadic intervals, and it is unlikely that the physical demands of work and the process of on the job rescues will be of sufficient frequency to provide adequate training to maintain, let alone increase, physical fitness. It is therefore in their opinion recommended that (1) standards of required physical fitness be developed and (2) mines rescue personnel undergo regularly training (and assessment) in order to maintain these standards, we have design our own pre physical training method.

In another study made by $\mathrm{H}$. Xie and T. Yan, from North China Institute of Science and Technology, Hebei, China, and published in Progress in Mine Safety Science and Engineering II, 2014 Taylor and Francis, London, pp. 583-586, in the paper called Mine rescue training programs and research. They have proposed an exercise prescription library, with the following prescription library project items: the collective and humanity. Collective classes include power quality training, endurance quality training, flexibility quality training, anti-sea-sikness training, responsive quality training and so on. Humanity classes are richer and more targeted [11].

\section{Research methodology}

\subsection{Methodology}

We have proposed a pre physical training procedure to be made by mine rescuer before the standard training test conducted in the INSEMEX Petrosani laboratory. We have proposed our physical training exercise on the fact that training made changes in cardio respiratory result of the trained person. We know the fact that a trained person has a $40-50 \mathrm{bpm}$, while a not trained person has a 70-76 bpm during the tests. We have used for our research 20 Polar Heart Rate Monitors sport watches and the Polar Pro Trainer Software for evaluating the results. Polar offers some of the most advanced heart-rate based training equipment in the world. It includes heart rate monitors for running, fitness \& cross-training, as well as GPS-enabled cycling computers and sports watches for endurance training. We have used these sport watches for measuring the effort of the mine rescuers during the training programs. Polar sport zones offer a new level of effectiveness in heart rate-based training. Training is divided into five sport zones based on percentages of your maximum heart rate. With sport zones, we can easily select and monitor training intensities and follow Polar's sport zones-based training programs.

\subsection{The training place}

We have used for our research the Laboratory for Risk-Rescue Operations of the Romanian National Institute for Research and Development in Mine Safety and Protection to Explosion. Here the INSEMEX researcher aimed at modification of bio-psycho-physiological parameters of intervention and rescue personnel during specific actions. Given the extremely difficult and dangerous conditions in the operating bands of rescue is necessary to conduct more research on how the body and the system respond and adapt to and psyche of rescuers in these environments.

\subsection{The instruments}

We have used for our research 20 Polar Heart Rate Monitors sport watches and the Polar Pro Trainer Software for evaluating the results, see figure 1. 
Figure 1: Polar Heart Rate Monitors and GPS sport watches and Polar Pro Trainer Software
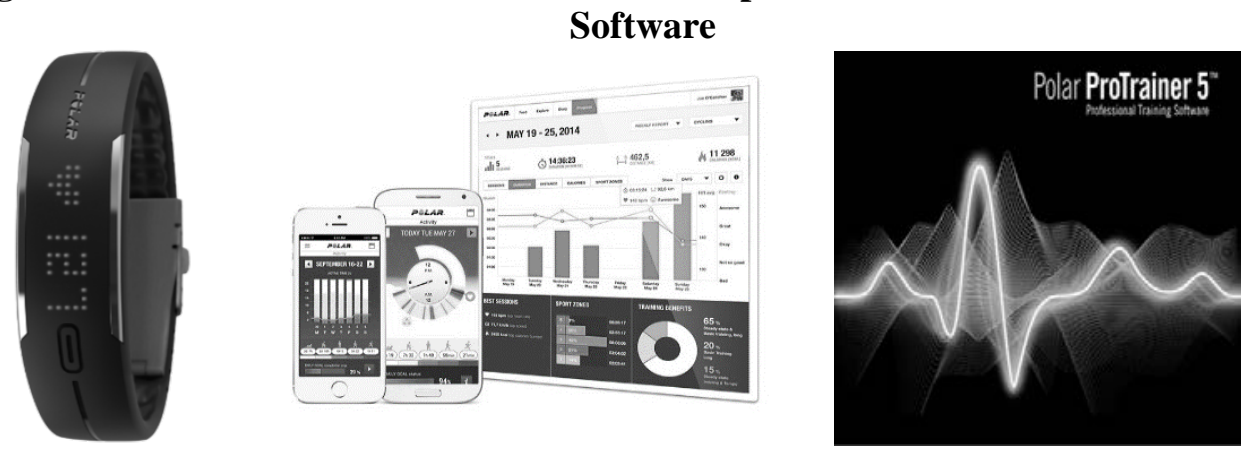

Polar offers some of the most advanced heart-rate based training equipment in the world. It includes heart rate monitors for running, fitness \& cross-training, as well as GPS-enabled cycling computers and sports watches for endurance training. We have used these sport watches for measuring the effort of the mine rescuers during the training programs. Polar sport zones offer a new level of effectiveness in heart rate-based training [5], [6]. Training is divided into five sport zones based on percentages of your maximum heart rate. With sport zones, we can easily select and monitor training intensities and follow Polar's sport zones-based training programs, as you can see it in figure 2.

Figure 2: Heart rate beats per minutes, according to age and training intensity

(Source www.polarthai.net )

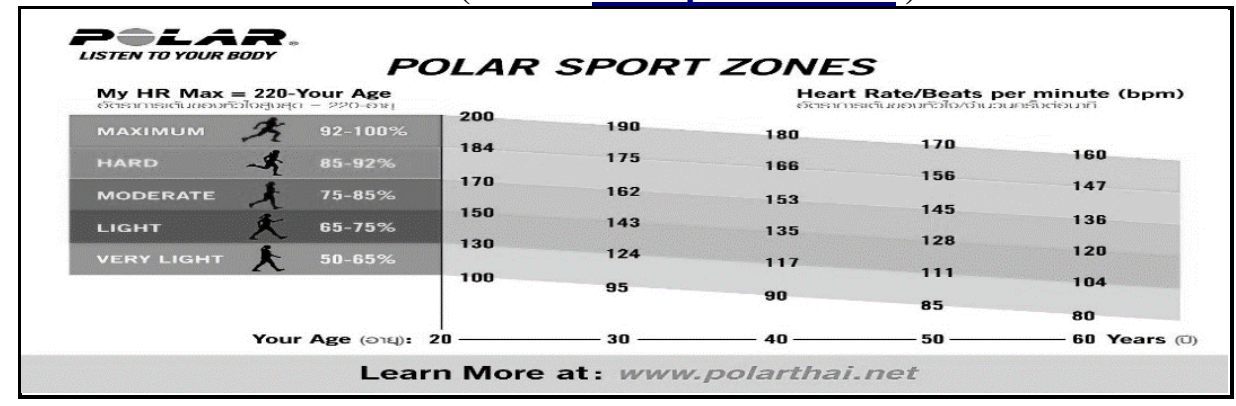

Maximum heart rate (HRmax) is the highest number of beats per minute (bpm) that heart can reach during maximum physical exertion. It is individual and depends on hereditary factors and age. If we wish to reliably measure the intensity of the training, it's important to know how hard the heart can work when it's pumping at its maximum capacity. The more accurately we know the HR max the more accurately we can define the heart rate limits or sport zones needed to use to get the optimal training benefit. If we overestimate the HR max, the heart rate limits within which we train will be higher than they should be. If we underestimate our HR max, then we will be training at too low intensities. Most Polar models allow direct entry of a HR max value. If we don't know our HR max, most models use the age-based formula (220 - age $=$ HR max) [4].

\subsection{The pre physical training procedure proposed}

We have designed a procedure containing six training models: Body Building, Method of isometric efforts, Method of Interval Training, Volume variation method, Structured method for basic grip and release and Specific work method, presented in table 1.

Body Building. Bodybuilding represent the use of progressive resistance exercise to control and develop one's musculature. The method contains strength training through weights or elastic/hydraulic resistance. Weight training aims to build muscle by prompting two different types of hypertrophy: sarcoplasmic hypertrophy and myofibrillar hypertrophy.

Isometric efforts. Isometric sessions should be used just like regular strength training with peak frequency for the week at around three to four sessions. It can take the nervous system up to five times longer to recover than the muscular system, so the effects of isometric training can last a long time after the session. Isometric contraction occurs when the muscle tenses while not changing length. Examples of this are poses in body building or pushing against an immoveable object such as a wall.

Interval Training. Interval running enables the athlete to improve the workload by interspersing heavy bouts of fast running with recovery periods of slower jogging. The athlete runs hard over any distance up to $1 \mathrm{k}$ and then has a period of easy jogging. During the run, lactic acid is produced and a state of oxygen 
debt is reached. During the interval (recovery), the heart and lungs are still stimulated as they try to pay back the debt by supplying oxygen to help break down the lactates. The stresses put upon the body cause an adaptation including capillarisation, strengthening of the heart muscles, improved oxygen uptake and improved buffers to lactates. All this leads to improved performance.

Volume variation method. The Variation Principle suggests that minor changes in training regimens yield more consistent gains in sport performance. Training programs for virtually every sport include variations in intensity, duration, volume, and other important aspects of practice [2], [3], [5].

Table 1: Physical training procedure

\begin{tabular}{|c|c|c|c|c|c|}
\hline $\begin{array}{l}\text { Motility } \\
\text { Qualities }\end{array}$ & Physical models of training & Data & Data & Data & Data \\
\hline \multirow[t]{2}{*}{ Strength } & $\begin{array}{l}\text { Method of segmental efforts } \\
\text { Body Building }\end{array}$ & $\frac{4 ; 7 ; 9 ; 10 ;}{3 x}$ & $\frac{2 ; 3 ; 5 ;}{3 x}$ & $\frac{6 ; 8 ;}{3 x}$ & $\frac{4 ; 7 ; 9 ;}{3 x}$ \\
\hline & Method of isometric efforts & $\frac{1 ; 2 ; 4 ;}{6 " x 3}$ & $\frac{3 ; 5 ; 6 ;}{6 " x 3}$ & $\frac{2 ; 5 ;}{6 " x 3}$ & $\frac{1 ; 3 ; 5 ;}{6 " x 3}$ \\
\hline \multirow[t]{2}{*}{ Endurance } & Method of Interval Training & $\frac{1 ; 4 ;}{1 x}$ & $\frac{3 ;}{2 x}$ & $\frac{1 ; 2 ;}{1 \mathrm{x}}$ & $\frac{1 ; 3 ;}{1 \mathrm{x}}$ \\
\hline & Volume variation method & & $\frac{4 ;}{1 x}$ & $\frac{5 ;}{1 x}$ & $\frac{5 ;}{1 x}$ \\
\hline \multirow[t]{2}{*}{ Skill } & $\begin{array}{l}\text { Structured method for basic grip } \\
\text { and release }\end{array}$ & $\frac{1 ; 3 ;}{2 x}$ & $\frac{2 ;}{2 x}$ & $\frac{3 ;}{2 \mathrm{x}}$ & $\frac{5 ;}{2 x}$ \\
\hline & Specific work method & $\frac{1: 2 ;}{2 x}$ & $\frac{1: 3}{2 x}$ & $\frac{1: 4}{2 x}$ & $\frac{2: 4}{2 x}$ \\
\hline
\end{tabular}

\section{Results}

4.1. Initial stage - the standard test results - the 2012 periodical training session

We have tested 15 surface rescue miners and 6 underground rescue miners during their periodical training session made at INSEMEX Petrosani. Using Polar heart rate monitors watches we could notice a few syncope during the training. In the figure below we have presented the curve for the Heart Rate (HR) during a 90 minutes training program for two extreme cases of mine rescuers, during the 2012 training session. He have analyzed also the 90 discontinuous HR results for all the 90 minutes of the exercise for all the 21 mine rescuers.

We have observed the heart rate measured in bites per minute in 2012 year, for six underground mine rescuers, during the first 10 minutes of the training and the next ten minutes of training, as we can see in figure 3 and figure 4.

Figure 3: Heart Rate for underground mine rescuers tested during their periodical training session in Risk-Rescue Operations Laboratory INSEMEX Petrosani, September 2012 (first ten minutes of the 90 minutes of the training program)

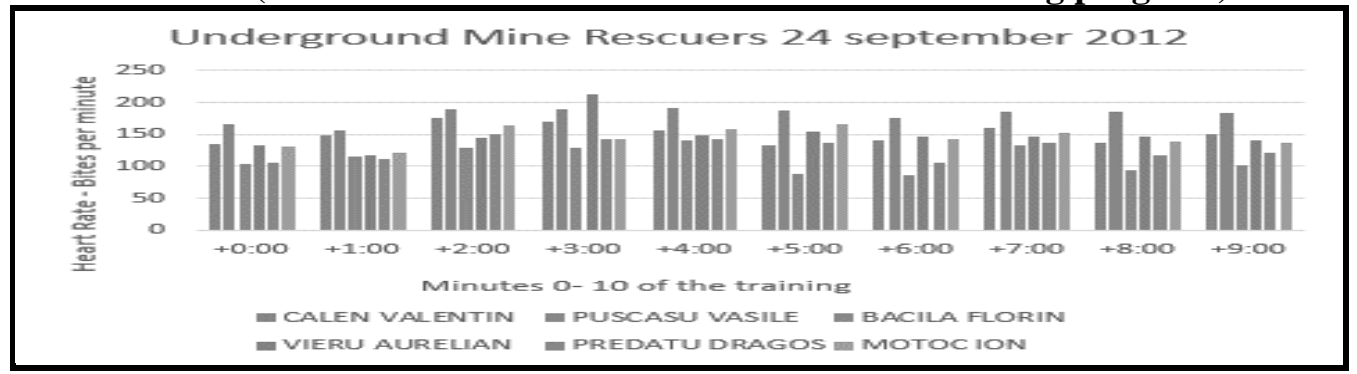

Figure 4: Heart Rate for underground mine rescuers tested during their periodical training session in Risk-Rescue Operations Laboratory INSEMEX Petrosani, September 2012 ( minutes 10-20 of the 90 minutes of the training program)

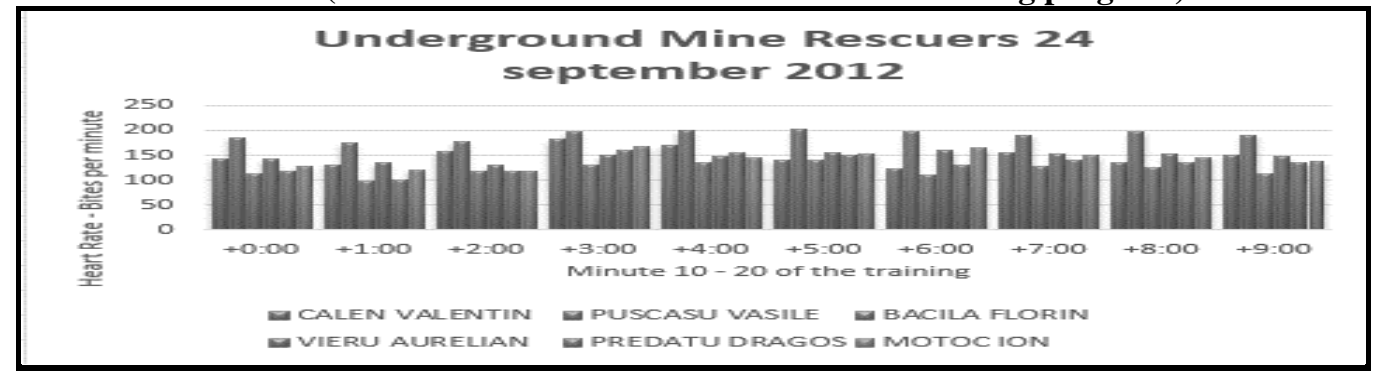


We have observed the heart rate measured in bites per minute in 2012 year, for eight surface mine rescuers, during the first 10 minutes of the training and the next ten minutes of training, as we can see in figure 5 and figure 6.

Figure 5: Heart Rate for surface mine rescuers tested during their periodical training session in Risk-Rescue Operations Laboratory INSEMEX Petrosani, November 2012 ( first ten minutes of the 90 minutes of the training program)

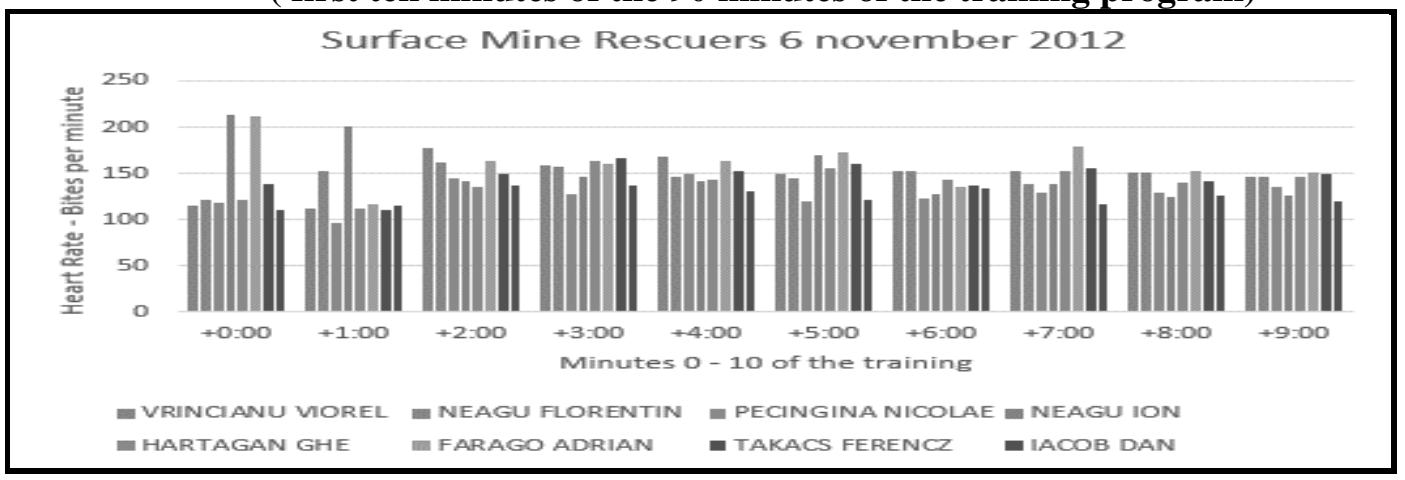

Figure 6: Heart Rate for surface mine rescuers tested during their periodical training session in Risk-Rescue Operations Laboratory INSEMEX Petrosani, November 2012 ( minutes 10-20 of the 90 minutes of the training program)

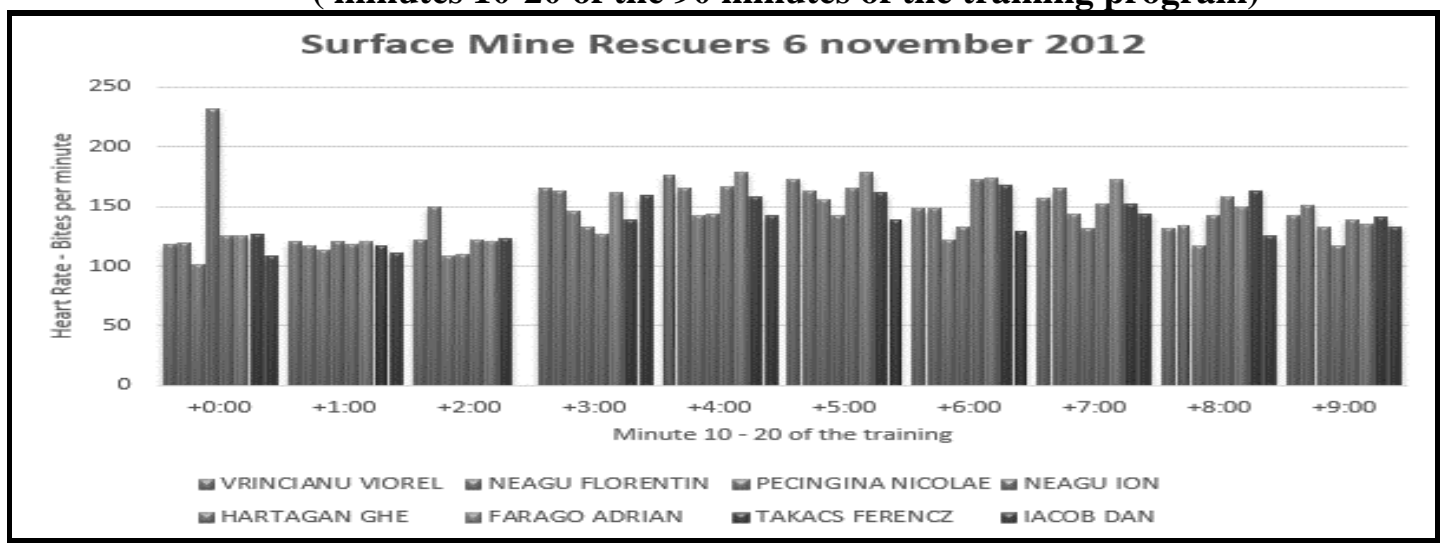

4.2. Final stage - the improved test results - after the implementation of the pre physical training procedure - the $\mathbf{2 0 1 4}$ periodical training session

We have selected four surface mine rescuers, having an improvement of the heart beat rate between 11-13 percent for the two years. Below we present the improvement of the heart beat rate for one of them, for the first ten minutes of the exercise, relevant for a surface mine rescuer $(11 \%$ decrease of the heart rate), the Polar heart rate monitors watches chart and the regression analysis for the 10 minutes of the measurement ( $\mathrm{R}=0,952$-very good link) as we can see in figure 7 and 8 .

Figure 7: Improvement of the heart beat rate, for the first ten minutes of the exercise and the Polar heart rate monitors watches chart
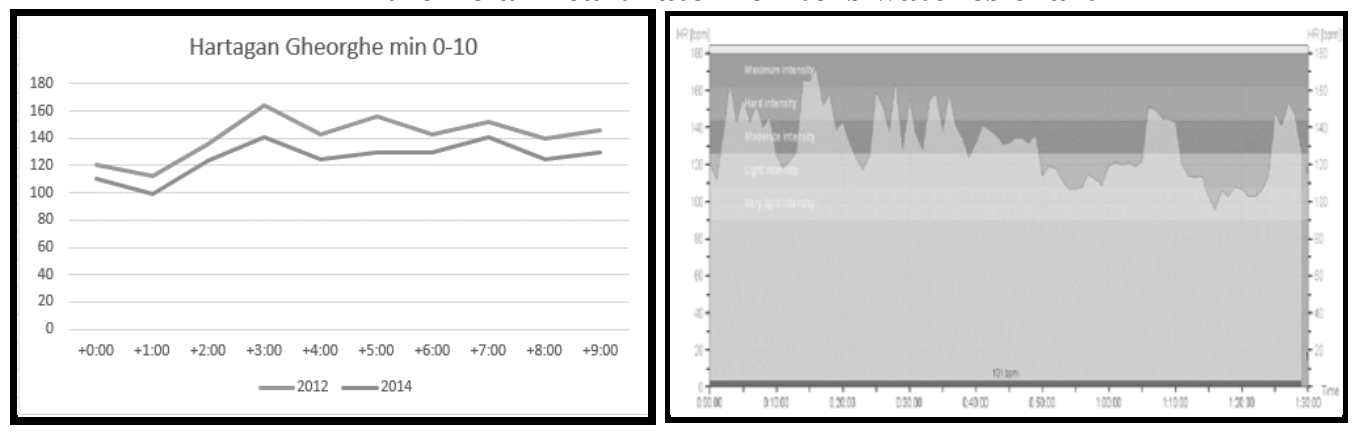
Figure 8: The regression analysis for the 10 minutes of the measurement

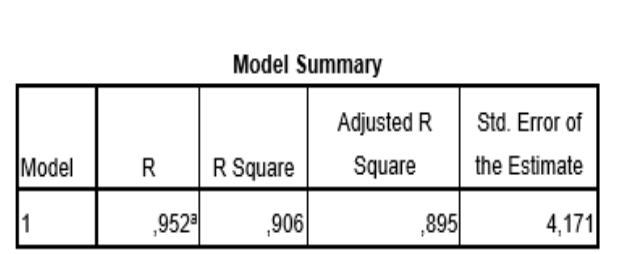

a. Predictors: (Constant), hbr_5_hartagan

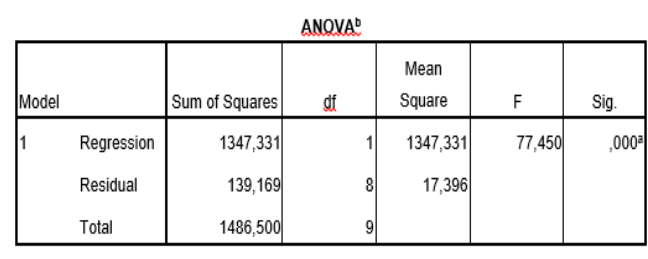

a. Predictors: (Constant), hbr_5_hartagan

b. Dependent Variable: hbr_5_2014

\section{Conclusions}

We have proposed a set of training exercises, in fact a pre training program to be made by the mine rescuers before the periodical training session. In 2014 year we have tested the same mine rescuers, tested in 2012 without a pre training program and we could observe a 7\% decrease in the heart rate beating. This decrease could conduct to a better efficiency in the mine rescuers saving activity.

\section{Acknowledgments}

Our research was possible with the support of the general manager of INCD INSEMEX National Institute for Research and Development in Mine Safety and Protection to Explosion, PhD Eng. Artur Gaman,

\section{References}

- Barlow A., Clarke R., Johnson N., Seabourne B., Thomas D. and Gal J., Effect of massage of the hamstring muscle group on performance of the sit and reach test, Br Journal of Sports Medicine, no.38, pp. 349-351, (2004).

- Bealko S. B., Alexander D.W., Chasko L. L. and Grayson R L, Mine rescue training facility inventory - compendium of ideas to improve, 2009.

- Conti R. S., Chasko L. L. and Stowinsky L. D., Mine rescue training simulations and technology, Proceedings of the Fifth Annual Conference of the International Emergency Management Society, pp. 453-464, (1998).

- Costa C., Stelescu I., Increasing the Efficiency of the Training Programs for the Mine Rescue Teams, Annals of the University of Petroşani, Economics, Volume 14, Part 1, (2014).

- Costa C., Pupazan D., Modern Physical Training Methods for Mine Rescuers, Annals of the University of Petrosani, Mining Engineering, Volume 15, (2014).

- Edelhauser E., Ionica A., Leba M., Modern Management Using IT \& C Technologies in Romanian Organizations, Transformations in Business \& Economics, Vilnius University, Lithuania, Vol. 13, No 2B (32B), pp. 742-759, (2014).

- Edelhauser E., Lupu Dima L., Management Information Systems. Past And Present in Romanian Organizations, The 11th International Conference on Informatics in Economy, Education, Research \& Business Technologies (IE 2012), pp. 459-463, (2012).

- Găman A. G., Procedures and regulations of the formations for intervention and operation in toxic/explosive/flammable environments, (in Romanian), INSEMEX Publishing House, Petrosani, Romania, (2009).

- Palmer L. M., Epler M. E., Fundamentals of musculoskeletal assessment techniques. 2nd edition, Philadelphia, Lippincott, (1998).

- $\quad$ Stewart I.B., McDonald M.D., Hunt A.P. and Parker T.W., Physical capacity of rescue personnel in the mining industry, Journal of Occupational Medicine and Toxicology, (2008).

- Xie H., Yan T., Mine rescue training programs and research, Progress in Mine Safety Science and Engineering II, Taylor and Francis, London, pp. 583-586, (2014). 